\title{
Religiosity and Yoga in Parkinson's Disease Patients
}

ISSN: 2637-7934

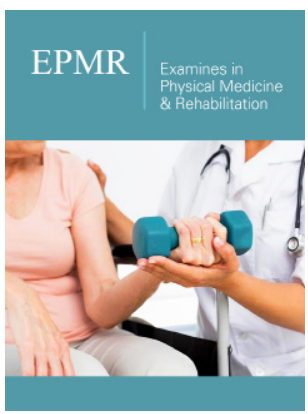

*Corresponding author: Docu Axelerad Any, Department of General Medicine, Constanta, Romania

Submission: 漹 March 18, 2019

Published: 眥April 22, 2019

Volume 2 - Issue 3

How to cite this article: Docu Axelerad A, Alina S, Docu Axelerad D. Religiosity and Yoga in Parkinson's Disease Patients. Examines Phy Med Rehab.2(3). EPMR.000539.2019.

DOI: 10.31031/EPMR.2019.02.000539.

Copyright@ Docu Axelerad Any, This article is distributed under the terms of the Creative Commons Attribution 4.0 International License, which permits unrestricted use and redistribution provided that the original author and source are credited.

\author{
Docu Axelerad Any ${ }^{1 *}$, Alina Stroe ${ }^{2}$ and Docu Axelerad Daniel ${ }^{3}$ \\ ${ }^{1}$ Department of General Medicine, Romania \\ ${ }^{2}$ Clinical hospital Constanta, Romania \\ ${ }^{3}$ Department of Kinethoteraphy, Romania
}

\begin{abstract}
Objectives: This study was led to analyze the clinical correlates considering the effectiveness of yoga exercises and religiosity on Parkinson's disease (PD) patients.
\end{abstract}

Methods: Measures of mood, neuropsychological function and motor activity were assessed in 14 cases with Parkinson's disease and 12 persons with vestibular syndrome. PD patients received L-Dopa and dopaminergic agonists treatment.

Results: The improvements in the functional activities during the study period were not clinically significant. Subjectively, the participants acquired delectation and relaxation from the yoga sessions.

Keywords: Parkinson's disease; Religiosity; Yoga; Vestibular syndrome

Abbreviations: PD: Parkinson's Disease; MMSE: Mini-Mental State Examination

\section{Introduction}

Parkinson's disease affects neurological, physiological and psychological functions and the quality of life. The parkinsonian patient's most known symptoms are rigidity, bradykinesia and tremors. The main neuroanatomical pathology implicates the loss of dopaminergic cells in the substantia nigra, as in the ventral tegmental aria [1]. On the other hand, the dopaminergic loss reveals another range of symptoms, non-motor ones that occur in PD, such as: depression, apathy, sleep disorders and generally a social isolation as a defense mechanism. Recent studies have shown that a polymorphism on the dopamine's receptor gene, DRD4, has been encountered to be considerable related with measures of spirituality and self-transcendence on a personality scale [2]. The frontal lobe is densely innervated by dopaminergic fibers with the origin in the ventral tegmental aria and in the substantia nigra (Randolph-Scwartz) and studies of Namara [3] have shown that changes in prefrontal function can be associated with changes in religious behaviors such as prayer and meditation. However, there are no published reports of religiosity-related symptoms in Parkinson's disease. The term yoga is descended from the Sanskrit verb 'yuj', meaning 'to unite', with the meaning of uniting the body, mind and spirit. Yoga therapeutics offers a specifically intense practice through the integration of the central nervous system with the entire human experience. Parkinson's disease can affect walking and balance, and it is estimated that over $70 \%$ of people with Parkinson's disease fall within a given year, therefore yoga exercises- that improve the muscles' strength and the position of the body- might be more than helpful for the PD patients. A recent study published in Evidence-based Complementary and Alternative Medicine suggests that yoga can be helpful to people with Parkinson's disease. In the light of these facts, we therefore sought to conduct a study to investigate the correlations that may exist between using religion/yoga and the improving state of mind into PD patients' life.

\section{Materials and Methods}

All 14 patients ( 6 of whom were female), with PD were recruited from a neurologic private clinic. Patients were individually diagnosed by Dr Docu Axelerad Any, director of the clinic and all met standard criteria for idiopathic PD. All patients were at Hoehn-Yahr stage II, without 
dementia, hallucinations or dyskinesia. The control group-12 patients ( 6 of whom were female), with vestibular syndrome, without dementia were recruited from a neurologic private clinic. The religiosity was evaluated with the following questionnaires: Mini-Mental State Examination Folstein, Beck Depression Inventory Beck, Webster. The two groups were advisedly elected to not differ significantly in terms of age (PD mean: 64,1; range: 60-68; control's mean: 63,6; range: 60-69). The results of the questionnaires before yoga/meditation are:

a) Mean Mini Mental State Exam (MMSE) Score was 27,5 for PD patients and 28,3 for healthy controls.

b) The mean Webster scale results for the PD patients is 7,7 and for the controls is 0,4 .

c) The results for the Beck scale were: for the PD patients the mean was: 7,9; meanwhile for the control group, the mean was: 3,2 (Table 1).

Table 1: Patients' scores on the questionnaires before yoga and meditation.

\begin{tabular}{|c|c|c|}
\hline & PD Patients & Controls \\
\hline Age range & $60-68$ & $60-69$ \\
\hline Age mean & 64,1 & 63,6 \\
\hline MMSE score range & $25-30$ & $26-30$ \\
\hline MMSE score mean & 27,5 & 28,3 \\
\hline Webster scale range & $5-10$ & $0-2$ \\
\hline Webster scale mean & 7,7 & 0,4 \\
\hline Beck scale range & $3-4$ & $1-8$ \\
\hline Beck scale mean & 7,9 & 3,2 \\
\hline
\end{tabular}

A half of the PD and the control group patients were assessed to do a session of 15 minutes of yoga per day (including exercises and breathing movements) and to another half, the assessment was to meditate and pray for 10 minutes per day. The time of evaluation was 6 months. The tests (the MMSE, the Beck Scale and the Webster Scale) were conducted once a month and the results centralized. The poses used by the patients were all chair-related, as in, the pose was done on a chair or in the proximity of a chair, even using a chair. An assistant was there the whole time, helping with the movements or supervising the movements (Table 2).

Table 2: The main poses were easy to do, using the most flexion and extension movements and examples of the poses.

\begin{tabular}{|c|c|}
\hline 1. Seated cat & $\begin{array}{r}\text { With hands on the knees; the patient inhales as } \\
\text { the chest and abdomen move forward; exhales and } \\
\text { contracts the belly area. }\end{array}$ \\
\hline $\begin{array}{l}2 . \quad \begin{array}{c}\text { Core twists } \\
\text { with hands on } \\
\text { shoulders }\end{array} \\
\text { 3. } \begin{array}{c}\text { Lateral move- } \\
\text { ments of the spine }\end{array}\end{array}$ & $\begin{array}{r}\text { The patient inhales on the center and exhales as } \\
\text { turning the chest to each side. } \\
\text { the other arm as turns the face down toward the } \\
\text { lower shoulder, taking three long, deep breaths. }\end{array}$ \\
\hline
\end{tabular}

\begin{tabular}{|c|r|}
\hline 4. Leg swings & $\begin{array}{r}\text { While standing, the patient will swing one leg for- } \\
\text { ward and back, catching and then holding under } \\
\text { the knee for three breaths. The patient will use a } \\
\text { support if needed for balance. }\end{array}$ \\
\hline 5. Arm circles & $\begin{array}{r}\text { The patient keeps the arms outstretched in the } \\
\text { front and circles the right arm forward as the left } \\
\text { arm circles back. }\end{array}$ \\
\hline 6. Hip stretch & $\begin{array}{r}\text { Remaining seated the patient puts the ankle over } \\
\text { the thigh in a figure-four shape. }\end{array}$ \\
\hline
\end{tabular}

\section{Results and Discussion}

According to the American Parkinson Disease Association (ADPA), yoga therapy has been shown to visibly reduce tremors and improve the motility of the patient. In our study, the PD patients-yoga participants reported to have more energy and three patients reported a tremor reduction immediately following yoga. The most common beneficial fact reported was the relaxed state of body and mind, with less fatigue, mirroring in the positive social relationship building and improved mood. Yoga is one of the most beneficial complementary therapies for Parkinson's disease, helping to increase flexibility, improving posture; loosening muscular contractures; build (or rebuild) confidence; and the most of all: enhancing the quality of life. Although it was told the patients that certain yoga poses target specific muscle groups, which the patient can use to help control tremors and that yoga may also be used in practice to help increase mobility, flexibility, and strength, not many of them were willing to repeat the poses, instead of it they were more focused on breathing. Exercise intervention has welldocumented beneficial effects on PD symptoms and quality of life. Some forms of exercise have improved the perceived health status, fall risk and motor performance [4]. Yoga also improves respiratory pressure [5] while yogic breathing techniques have an immediate effect on lowering blood pressure in healthy people.

The results of the three tests conducted amongst the patients have shown a slight improvement, month by month, until, at the end of the testing period, we obtained higher scores of our patients' questionnaires. Performing the MMSE, at the end of the trial, in the yoga PD group, only 3 patients obtained higher scores (by 1 point), but in the group of control, only one person gained a higher by one point than the score in the beginning. Performing the MMSE at the end of the study, in the groups that practiced meditation and prayers, the results were similar, only one person of both PD patients and vestibular syndrome patients, obtained a higher score. Regarding the Beck Depression Inventory, the results changed for every patient, especially for the ones with PD, which practiced yoga, so the differences between the initial score and the final score are 1 to 5 points; and for the control group the results ameliorated with 1 maximum 2 points for each patient. In the group that practiced meditation and prayers, only 4 PD patients have changed their responses and only 2 patients with vestibular syndrome have expresses changes in their state of mind. About the Webster scale, all the patients were classified with mild Parkinson's disease, 
having a total score between 5-10 points, after yoga, the score was changed for 4 patients, and after prayers and meditation the score was ameliorated for 1 patient [6].

\section{Conclusion}

This is a pilot study with a relatively small patient number and thus our conclusions should be treated with cautions. Both, the yoga programmed and the meditation/prayers, can improve the performance of a PD patient. Especially, the yoga poses can make a difference in quality of life for a patient, both physical and mentally. Although, the difference is not a significant one, this study gives us hope for a better life for PD patients and not only for them.

\section{References}

1. Agid Y, Javoy A, Ruberg M (1987) Biochemistry of neurotransmitters in Parkinson's disease. Butterworth and Co, New York, USA.
2. Comings DE, Gonzales N, Saucier G, Johnson JP, MacMurray JP (2000) The DRD4 gene and the spiritual transcendence scale of the character temperament index. Psychiatr Genet 10(4): 185-189.

3. Namara P (2001) Religion and the frontal lobes. Cambridge University Press, UK, Pp. 237-256.

4. Herman T, Giladi N, Gruendlinger L, Hausdorff JM (2007) Six weeks of intensive treadmill training improves gait and quality of life in patients with Parkinson's disease: a pilot study. Arch Phys Med Rehabil 88(9): 1154-1158.

5. Kulkarni DD, Bera TK (2009) Yogic exercises and health-a psycho-neuro immunological approach. Indian J Physiol Pharmacol 53(1): 3-15.

6. Colgrove Y, Sharma N, Kluding P, Potter D, Imming K, et al. (2012) Effect of Yoga on motor function in people with Parkinson's disease: a randomized, controlled pilot study. J Yoga Phys Ther 2: 1-11. 
For possible submissions Click below: 